\title{
EDITORIAL
}

\section{The Essential Role of Primary Care Professionals in Achieving Health for All}

Maria van den Muijsenbergh ${ }^{1,2}$

Chris van Weel ${ }^{1,3}$

'Radboud University Medical Centre, Radboud Institute of Health Sciences, Department of Primary and Community Care, Nijmegen, The Netherlands

${ }^{2}$ Pharos, Centre of Expertise on Health Disparities, Utrecht, The Netherlands

${ }^{3}$ Australian National University, Department of Health Services Research and Policy, Canberra, Australia

Ann Fam Med 2019;17:293-295. https://doi.org/10.1370/afm.2436.

I n October 2018, the World Health Organization (WHO) adopted the Declaration of Astana ${ }^{1}$ to strengthen primary health care to attain universal access to health care and better health for all. In May 2019, the governments of the 196 countries represented in the WHO World Health Assembly, ratified the Astana declaration. Although a promising development, the Declaration of Astana falls short by failing to acknowledge the family medicine professionals who should carry out its implementation. This commentary explores the opportunities and challenges that "Astana" presents for primary care and family medicine clinicians, who need to combine care for the individual with engagement with policy makers and public health officials to help highlight the professional contribution of primary care in the broader context of primary health care to secure person-centered, population-oriented integrated care.

\section{THE DECLARATION OF ASTANA}

The Declaration of Astana ("Astana") acknowledges the importance of primary health care as a core function in health systems for attaining universal health coverage, ${ }^{2}$ better health outcomes, and health equity. ${ }^{3}$ This declaration was recently endorsed by the World Health Assembly of $\mathrm{WHO}_{1}^{4,5}$ which further supports

Conflicts of interest: authors report none.

\section{CORRESPONDING AUTHOR}

Chris van Weel

Radboud University Medical Center

ELG-117

PO Box 9101

Nijmegen 6500 HB The Netherlands

chris.vanweel@radboudumc.nl its authority. It provides welcome support for health reforms around the world: with the unanimous backing of all WHO member countries, it aims to provide guidance for national governments to invest in primary health care for the improvement of quality and access of health care for their populations.

Family physicians and other primary care health professionals are an integral part of this effort. But how can we make Astana work, not despite, but because of our daily work?

\section{FROM ALMA-ATA TO ASTANA}

The Declaration of Astana grew out of the 1978 Declaration of Alma-Ata when WHO first adopted a policy on primary health care as the most important strategy to achieve accessible good quality health care for all. ${ }^{6}$ Guided by values of solidarity and equity, WHO members reached the consensus that all people in all countries have the fundamental right to health, and that governments have the responsibility to provide it. This agreement signified a shift from thinking of health in terms of diseases towards attention to social determinants of health. ${ }^{7}$ For the first time, it placed the health needs of people and populations at the center. Primary health care in this view consists of 3 pillars: community empowerment, multisectoral action to address the social determinants of health, and integration of primary care and public health. ${ }^{8}$

Alma-Ata never lost its conceptual attractions, but also never fulfilled its political potential. Since 1978, research has proved that health systems with strong primary health care lead to better health at lower costs and are essential to guarantee access to health care for all., ${ }^{910}$ This evidence established a renewed WHO focus on primary health care, with a call to invest in 
training of primary care professionals. ${ }^{11}$ Impressive improvements in the health of populations through access to primary care have been achieved, notably in Brazil $^{12}$ and Thailand. ${ }^{13}$

There are several reasons why the high expectations of Alma-Ata did not succeed, however. In some countries, the pursuit of short-term results caused governments to focus on "limited, selective primary health care" with disease-oriented vertical programs, like vaccination programs, ${ }_{1}^{14}$ without integration among programs. ${ }^{15}$ In other countries neo-liberal health policies led to less comprehensive care services and more focus on clinical services ${ }^{16}$ causing conflict between structural conditions and professional values and social views on health. ${ }^{17}$ For sustainable care, horizontal integration is essential, where prevention, cure, and care for all health problems in all patients is combined. In addition, there was too much focus on health systems' structure without acknowledgment of the importance of professionalism of the providers of care to add performance to structure. ${ }^{18}$

The Astana declaration may be better timed, with its concerns about global sustainable development and planned actions to address this. ${ }^{19}$ Improvement of health is seen as a condition for social-economic development. In addition, health promotion now brings influential non-health care stakeholders to the table, such as the United Nations, the World Bank, and the Bill and Melinda Gates Foundation, and with them the hope for concrete results.

\section{THE IMPORTANT ROLE OF PRIMARY CARE WITHIN PRIMARY HEALTH CARE}

To understand the aims of Astana it is important to be aware of the distinction between primary care and primary health care. Primary care, which refers to the work of health professionals like family physicians, is a part of primary health care's broader aims. The recent draft for an operational framework on primary health care specified the role of primary care as "meeting people's health needs through comprehensive promotive, protective, preventive, curative, rehabilitative and palliative care throughout the life course, strategically prioritizing key health care services aimed at individuals and families through primary care and the population, with essential public health functions as the central elements of integrated health services". ${ }^{20}$

Indeed, family physicians, rooted in their community, and primary care teams have unparalleled data and ethnographic knowledge of local disease, trends, and social drivers. They are well placed to support public health teams in assessing and addressing causes of disease. ${ }^{21}$ There is an essential role for the family physician beyond the provision of individual curative care, in achieving health for all. What the optimal role is, however, and who should perform it is still open for discussion.

In implementing Astana, it is essential that family physicians, nurses, midwives, and other allied health professionals present their perspectives and competencies. The quality and effectiveness of primary health care, and with it the ability to realize universal health coverage is determined by their professionalism. ${ }^{22}$ And here is the great disappointment of Astana. As in 1978 in Alma-Ata, the Astana declaration fails to acknowledge the professionals that should carry out its implementation-suggesting that the mere provision of health care structures would do the trick. This lack of acknowledgment for the professionalism of family medicine clinicians is even more painful now than in 1978, given the strong development the field of family medicine has seen in these 40 years.

The problem is that in many health systems family physicians and other professionals do not have the instruments to relate individual care to populations or communities. Few countries provide a practice list that facilitates this. And where this is the case, there is a need to strengthen the multi-disciplinary composition of teams responsive to local communities. With its 41,000 multidisciplinary teams caring for 130 million citizens, Brazil is a strong example of primary health care with expanded coverage by social insurance and community-based health insurance in low-income countries. At the same time, it is important for primary health care to emphasize its contribution to health and welfare, apart from universal health care. ${ }^{23}$

General population health data need translation to specific community needs to help primary health care address social determinants of health as part of individual care. At the moment, many key indicators for health care do not address the values of family medicine: continuity of care, person-and-population centeredness, comprehensive care. To get a reliable picture of the effects of primary care, indicators are needed that address these values. ${ }^{24}$ It is also crucial to translate the complexity of primary care into policy. This complexity exists in the organic coherence of care for the individual with multisectoral actions aimed at prevention and enhancement of health and well-being.

\section{WHAT CAN INTERNATIONAL ORGANIZATIONS OF PRIMARY CARE AND FAMILY MEDICINE DO TO MAKE ASTANA WORK?}

With renewed energy, primary care should continue what it has been pursuing over the last decades: advocacy for comprehensive primary care for individuals 
and communities as the core function in health systems and the strengthening of its professionalism through teaching, training, research, and practice development. But most urgently, we must amend what has been left out of the Astana declaration: engagement with policy makers and public health to detail the professional contribution of primary care in the broader context of primary health care to secure person-centered, population-oriented integrated care. This asks for transformation from medical care to intersectoral collaboration, and towards multidisciplinary teamwork to provide the necessary skills to address health problems in connection with social determinants of health. ${ }^{20}$ This should be a leadership priority for international and national academic primary care organizations and not left to the discretion of individual family physicians and other primary care professionals. ${ }^{25}$ If we achieve this transformation, we will be able to train and retain adequate numbers of family physicians with appropriate skill mix, able to work in a multidisciplinary context, in cooperation with nonprofessional community health workers to respond effectively to people's health needs. ${ }^{10,25}$

To read or post commentaries in response to this article, see it online at http://www.AnnFamMed.org/content/17/4/293.

Key words: Alma-Ata; Astana; Declaration of Astana; primary health care; primary care

\section{References}

1. World Health Organization. Declaration of Astana: from Alma-Ata towards universal health coverage and the sustainable development goals. Proceedings from the Global Conference on Primary Health Care; October 25-26, 2018; Astana, Kazakhstan. https:// www.who.int/docs/defaultsource/primary-health/declaration/gcphcdeclaration.pdf.

2. World Health Organization. Sustainable Development Goal 3: Health. Geneva, Switzerland: World Health Organization; 2017. https:// www.who.int/topics/sustainable-development-goals/targets/en/. Accessed Mar 6, 2019.

3. Starfield B, Shi L, Macinko J. Contribution of primary care to health systems and health. Milbank Q. 2005;83(3):457-502.

4. Binagwaho A, Ghebreyesus TA. Primary healthcare is cornerstone of universal health coverage. BMJ 2019; 365. doi: https:// doiorg/10.1136/bmj.l2391

5. WHA Resolution universal health coverage and primary health care of May 29, 2019. http://apps.who.int/gb/ebwha/pdf_files/WHA72/ A72_JOUR1-en.pdf.

6. World Health Organization. Declaration of Alma Ata. Geneva, Switzerland: World Health Organization; 1978. www.who.int/ publications/almaata_declaration_en.pdf. Accessed Mar 6, 2019.

7. Commission on Social Determinants of Health. Closing the Gap in a Generation: Health Equity Through Action on the Social Determinants of Health. Geneva, Switzerland: World Health Organization, 2008. http://apps.who.int/iris/bitstream/handle/10665/43943/97892415 63703_eng.pdf;jsessionid =4B2D91D4D9AC4E0188108B8C846F 953A? sequence =1. Accessed Dec 10, 2018.
8. Ghebreyesus TA, Fore H, Birtanov Y, Jakab Z. Primary health care for the 21st century, universal health coverage, and the Sustainable Development Goals. Lancet. 2018;392(10156):1371-1372.

9. Starfield B. Is primary care essential? Lancet. 1994;344(8930): 1129-1133.

10. Kringos D. The strength of Primary Care in Europe. Utrecht, Thesis, University of Utrecht, 2012. www.nivel.nl/sites/default/files/bestanden/Proefschrift-Dionne-Kringos-The-strength-of-primary-care.pdf. Accessed Dec 10, 2019.

11. World Health Organization. Primary health care, including health system strengthening, Resolution WHA62.12. Sixty-Second World Health Assembly. May 22, 2009. http://www.who.int/hrh/resources/ A62_12_EN.pdf. Accessed Dec 10, 2018.

12. Claunara Schilling Mendonça. The Brazilian Unified Health System: primary health care in actionin: Kidd MR (ed). The Contribution of Family Medicine to Improving Health Systems: a guidebook from the World Organization of Family Doctors (2nd ed). Abington UK; Radcliffe; 2013.

13. Yongyuth $P$. Family medicine and community orientation as a new approach of quality primary care in Thailand. In: Kidd MR, ed. The Contribution of Family Medicine to Improving Health Systems: A Guidebook From the World Organization of Family Doctors. 2nd ed. Abington, UK; Radcliffe; 2013.

14. Hewa S. Sri Lanka's approach to Primary Healthcare: a success story in South Asia. Galle Medical Journal. 2011;16(2):24-30.

15. van Weel C, Kassai R, Qidwai W, et al. Primary healthcare policy implementation in South Asia. BMJ Glob Health. 2016;1(2):e000057.

16. Baum F, Freeman T, Sanders D, Labonté R, Lawless A, Javanparast $S$. Comprehensive primary health care under neo-liberalism in Australia. Soc Sci Med. 2016;168(168):43-52

17. Freeman T, Baum F. Labonté R, Javanparast S, Lawless A. Primary health care reform, dilemmatic space and risk of burnout among health workers. Health (London). 2018;22(3):277-297.

18. van Weel C, Kassai R. Expanding primary care in South and East Asia. BMJ. 2017;356:j634.

19. United Nations. Sustainable development goals: 17 goals to transform our world. http://www.un.org/sustainabledevelopment/ sustainable-development-goals/. Published 2015. Accessed Mar 6, 2019.

20. WHO/Unicef. Primary health care: transforming vision into action. Operational framework; draft for consultation. Geneva, Switzerland: World Health Organization; 2019.

21. Allen L. Leveraging primary care to address social determinants. Lancet Public Health. 2018;3(10):E466

22. van Weel $C$, Kidd MR. Why strengthening primary health care is essential to achieving universal health coverage. CMAJ. 2018; 190(15):E463-E466.

23. Giovanella L, Magalhães de Mendonça M, Buss $P$, et al. From AlmaAta to Astana: primary health care and universal health systems: an inseparable commitment and a fundamental human right. Cad. Saúde Pública. 2019;35(3):e00012219.

24. Primary health care performance initiative. http://phcperformanceinitiative.org/about-us/measuring-phc. Accessed Dec 10, 2018.

25. Galea S, Kruk ME. Forty years after Alma-Ata: at the intersection of primary care and population health. Millbank Q. 2019;19(2):383-386. 